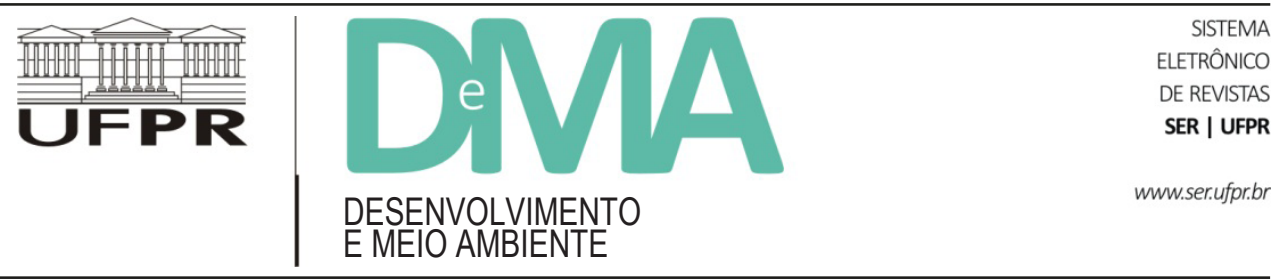

\title{
"Vozes da seca": lavradores, mediadores e poder público frente à estiagem no Semiárido do Jequitinhonha mineiro
}

\section{"Voices of the drought": farmers, mediators and public authorities in the face of drought in the semi-arid region of Jequitinhonha Mineiro} \author{
GOMES $^{2}$, Emília Pereira Fernandes da SILVA ${ }^{1}$

\footnotetext{
${ }^{1}$ Universidade Federal de Minas Gerais (UFMG), Belo Horizonte, MG, Brasil.

${ }^{2}$ Instituto Federal do Norte de Minas Gerais (IFNMG), Montes Claros, MG, Brasil.

*E-mail de contato: flaviagalizoni@yahoo.com.br
}

Flávia Maria GALIZONI ${ }^{1 *}$, Eduardo Magalhães RIBEIRO ${ }^{1}$, Vico Mendes Pereira LIMA², Natalino Martins

Artigo recebido em 15 de maio de 2020, versão final aceita em 4 de setembro de 2020, publicado em 18 de dezembro de 2020.

\section{RESUMO:}

\begin{abstract}
Entre 2013 e 2019, o Vale do Jequitinhonha, nordeste de Minas Gerais, enfrentou um período crítico de estiagem, com pouca chuva, concentrada em curtos períodos. Apesar de ser uma região que convive historicamente com irregularidades de precipitação, neste período a situação foi seriamente agravada pela degradação ambiental provocada pela monocultura de eucalipto e pela exploração mineral. No campo, os efeitos da seca e da privatização dos recursos recaíram principalmente sobre agricultores familiares, que mobilizaram as comunidades rurais organizadas e as agências de mediação, como sindicatos e associações, para ter acesso a programas públicos de abastecimento de água. Este artigo analisa iniciativas, originadas principalmente de órgãos estatais, mas também da sociedade civil, de provimento de água de comunidades rurais durante o período de seca. Usando entrevistas individuais e em grupo realizadas com os diversos atores envolvidos no assunto, examinou "vozes" dos agricultores e agentes públicos para entender como agricultores familiares atravessaram o período crítico de escassez. Os resultados indicam que, apesar da dimensão climática da seca alcançar toda a sociedade, a escassez incide de maneiras desiguais sobre grupos diferentes, revelando importantes filtros sociais e políticos. Destes filtros, o mais relevante é a gestão estatal da água.
\end{abstract}

Palavras-chave: agricultura familiar; água; semiárido, programas públicos; Vale do Jequitinhonha. 
ABSTRACT: The Jequitinhonha River valley, northeast of Minas Gerais, faced a critical period of drought, between 2013 and 2019, with little rain, concentrated in short periods. Despite being a region that has historically lived with irregularities in precipitation, in that period the situation was seriously aggravated by environmental degradation caused by eucalyptus monoculture and mineral exploitation. In the countryside, the effects of drought and the privatization of resources fell mainly on family farmers who mobilized organized rural communities and mediation agencies, such as unions and associations, to access public water supply programs. This article analyzes initiatives, originating mainly from state agencies, but also from civil society, to supply water to rural communities during the drought period. Using individual and group interviews carried out with the various actors involved in the subject, the "voices" of farmers and public agents were examined to understand how family farmers went through the critical period of scarcity. The results indicate that, despite the climatic dimension of the drought reaching the whole society, the scarcity affects different groups in different ways, revealing important social and political filters. Of these filters, the most relevant is the management of water by the State.

Keywords: family agriculture; water; semiarid; public programs; Jequitinhonha Valley.

\section{Introdução}

O vale do Jequitinhonha, nordeste de Minas Gerais, passou por um período crítico de estiagem entre 2013 e 2019. Foram anos de escassez e intermitência, com pouca chuva concentrada em curtos períodos, conformando, de acordo com lavradores da região, uma quadra de seca que também atingiu grande parte do Semiárido brasileiro.

Ao longo da história aconteceram outros ciclos de precipitação irregular no Jequitinhonha. Mas, neste período, o fenômeno alcançou grandes dimensões. Agricultores familiares, lideranças comunitárias e agentes públicos da região se manifestaram em reuniões, reportagens e manifestos sobre a singularidade dessa seca. Diferente dos períodos anuais e regulares de estiagem, dessa vez foi longa a duração, foram às dezenas as fontes perenes de água que secaram, a chuva, quando veio, foi tão pouca que em alguns anos a precipitação foi próxima da metade da média histórica. Foram 400 milímetros em 2015 em municípios como Chapada do Norte e Virgem da Lapa, de acordo com os secretários de
Agricultura dessas localidades, e 487 milímetros em Araçuaí (INMET, 2020).

Longos períodos de seca provocam dificuldades para toda a população, principalmente quando não existe planejamento ou estratégia sistemática de convivência. A população urbana enfrenta riscos de desabastecimento, aumenta a despesa do poder público com provimento de água e atendimentos de emergência, a produção da agricultura e da pecuária pode se reduzir muito, ou desaparecer, nas situações muito críticas. E, quando a seca afeta produção e renda da agropecuária do Jequitinhonha, atinge seriamente as condições de sobrevivência nessa região que, de acordo com os últimos censos, tem parte importante da população no meio rural. Como a população rural é formada majoritariamente por agricultores familiares produtores de alimentos, a seca prolongada compromete $\mathrm{o}$ abastecimento urbano, o autoconsumo e a poupança das famílias rurais.

A seca, portanto, não tem somente dimensão ambiental e climática: traz também ônus sociais e econômicos que se distribuem de forma desigual na sociedade, obedecendo ao recorte do poder econô- 
mico, seguindo as desigualdades de renda. Incidindo sobre a população rural formada por agricultores familiares, a seca revela com clareza esses filtros sociais que determinam acesso e abastecimento regular de água quando secam mananciais e grassa a escassez. Parte dos filtros tem origem na gestão pública da água; esta responde pela execução de programas de abastecimento: perfuração de poços artesianos, construção de barramentos e cisternas.

Nesse ponto, é preciso ponderar a relevância da política pública. Desde a Lei $\mathrm{n}^{\circ} 9.433 / 97$, conhecida como Lei das Águas, há uma tendência crescente para a privatização dos recursos hídricos e valorização da gestão empresarial, considerada eficiente e inovadora. Na quadra da seca de 2013/2019, diversos estudos, que serão analisados mais adiante neste artigo, apontaram dois efeitos derivados da privatização. Primeiro: a generalização da despesa estatal com provimento das populações rurais que não dispunham de fontes próprias, implicando na criação de programas públicos paliadores da escassez de água; muitos deles têm caráter compensatório, como os programas de bolsa estiagem, cestas básicas e abastecimento por caminhões-pipas. Assim, o ônus da privatização da água foi socializado, transformado em custos econômicos às vezes vultosos, compartilhados entre contribuintes. Segundo: a privatização instituiu conflito entre a política pública, baseada no atendimento individual, e a norma costumeira de gestão das águas que vigora no mundo rural, relacionada com a cultura local, baseada na solidariedade e na conservação do recurso.

Este artigo é um esforço de exploração dessas questões. Analisa as relações costumeiras entre agricultores e as águas, as normas de uso e partilha das comunidades rurais. Em seguida, aborda as iniciativas públicas, estatais e da sociedade civil, para abastecer a população rural durante a grande seca de 2013/2019 no Médio Jequitinhonha. Essas iniciativas apenas remediavam dificuldades de abastecimento, alimentando reflexões de sindicalistas e agricultores. Desse modo, o artigo analisa gestão e distribuição da água - por órgãos públicos, comunitários e privados -, sua efetividade para propiciar regularidade ao abastecimento doméstico e produtivo e sua articulação com a dinâmica que é própria da agricultura familiar. Mergulhando na polifonia que surge das falas de quem demanda, quem negocia e quem distribui a água na situação de crise, o artigo procura compreender vozes e razões que se manifestam em torno desse recurso vital.

\section{Secas, semiárido, Jequitinhonha}

Leopoldo Pereira, um dos cronistas mais afamados do vale do Jequitinhonha, escreveu na primeira década do século XX que as secas periodicamente atingiam a região. Aúltima, na década de 1890, provocara perda de colheitas, carestia, fome e migrações, e parte de suas consequências havia recaído sobre o poder público. A administração do município - que, na época, tinha o autor à frente como gestor - arcara com as despesas para alimentar famintos e enterrar migrantes baianos mortos por inanição. No entanto, o cronista destacava que a seca atingira de maneira desigual a vasta área que, então, era o município de Araçuaí: nas caatingas se perderam colheitas e criações, nas chapadas a altitude e a umidade natural favoreceram ao agricultor, nas matas a cobertura natural salvara os plantios. Nesses rápidos comentários, o autor resumiu dilemas que, no imaginário dos brasileiros, sempre são 
associados às secas: primeiro: perdas de colheitas, fome, migração; segundo: a ação pública; terceiro: os diferentes gradientes regionais de efeitos das secas (Pereira, 1969).

O primeiro comentário sobre a seca, a bem da verdade, não era exclusivo nem tampouco foi criado por Leopoldo Pereira. Alguns anos antes, Euclides da Cunha, em Os sertões, já fizera as mesmas observações e radicalizara a análise sobre suas consequências: a revolta e, principalmente, o conflito organizado materializado em Canudos, liderado por Antônio Conselheiro (Cunha, 1967). Vinha e vem daí o temor que desde então as secas suscitaram, por criar situações que podiam passar rapidamente da condição de sofrimento individual para a catástrofe que atinge grandes coletivos.

Exatamente por isso é que procede o segundo comentário de Pereira: a atuação das agências públicas era necessária porque alguma ação deveria ser desencadeada para mitigar o desastre coletivo. Num estudo clássico, dos anos 1930, Gilberto Freyre (1968) observava que às secas sempre associavam fomes e dramas humanos, e a estes, "obras contra as secas" - a esperada intervenção do poder público. De fato, como foi notado por tantos autores, desde o Império a seca cobrou uma resposta do Estado, que vinha sob a forma de ações emergenciais, barragens e frentes de trabalho (Andrade, 1986; Gomes, 2001). A ação mitigadora dos governos, ao longo da história, apresentou algumas características marcantes. Por um lado, perdurava apenas enquanto havia seca, para em seguida ser abandonada, esquecida e, talvez, retomada na próxima grande estiagem (Gomes, 2001). Por outro, implicava em ganhos para grupos políticos, pois o socorro, qualquer que fosse a forma que tomasse, era apropriado pelas chefias locais, transformado em recurso para troca de favores que perpetuavam o clientelismo e o mando político (Andrade, 1986; Silva, 2007).

Por fim, o terceiro aspecto sintetizado por Leopoldo Pereira revelou que o fenômeno climático da seca, que sempre se manifestava de forma desigual em áreas diferentes, se transformaria em fenômeno social. Anos depois, Manuel Correia de Andrade (1986) detalharia essa característica do Semiárido numa análise sofisticada, que consolidaria a noção de que existiam, na verdade, ambientes diversos sob este clima; tantos que, além de dar origem a grandes diferenças regionais, microrregionais e até municipais, também permitiam uma seca devastadora acontecer vizinha doutra área que desfrutava de prosperidade e fartura. Para Andrade, Semiárido não implicava necessariamente ocorrência de secas, pois algumas áreas tinham chuvas regulares; mas, mesmo ocorrendo secas, não havia obrigatoriamente falta de água e alimentos, pois existiam no Semiárido áreas pouco chuvosas mas bem-dotadas de rios e fontes naturais, que asseguravam produção continuada e qualidade de vida.

Assim, secas não iriam implicar sempre queda da produção, empobrecimento e migração. Em muitos registros históricos, a seca não afetou a produção de alimentos, como na seca de 1939 no Norte mineiro (Paula, 1957), ou não afetou a condição de vida da população, como nas denominadas "secas gordas", regadas com programas públicos nos anos do governo Lula (Costa, 2014). Além disso, como as secas têm periodicidade bastante regular no Semiárido - Gustavo Maia Gomes (2001) estimou que acontecem a cada 2,5 anos -, há perfeitamente condição de planejar ações adotando medidas preventivas que, em alguns sistemas de produção adaptados, já são como uma segunda natureza. Essas medidas, corriqueiras, funcionam 
como mecanismos de convívio com o fenômeno, que foram descritos em etnografias sobre agricultura familiar (Heredia, 1979; Dayrell, 2000; Galizoni, 2011; Medeiros, 2015) e estudos específicos sobre o semiárido (Guimarães Duque, 2004; Silva, 2007; Malvezzi, 2007).

Mas, às vezes, acontecem secas rigorosas, duradouras, com ampla abrangência espacial, que trazem consequências sérias sobre a produção, como esta do Jequitinhonha entre 2013/2019. Nestes casos, a seca revela ainda outro aspecto: a profunda desigualdade das consequências. $\mathrm{O}$ efeito é perverso principalmente sobre o patrimônio de agricultores familiares. A formação do patrimônio do agricultor do Semiárido segue uma estratégia ordenada, que passa do bem menor para o maior e do semovente para o estacionário (Ribeiro \& Galizoni, 2007). Compreende, por exemplo, plantar lavoura de mandioca, da mandioca fazer farinha, da venda de parte da farinha comprar uma dúzia de frangas, que recriadas se transformam em galinhas, que produzem pintos, que se vendem para comprar leitões, que, vendidos, se convertem numa vaca, que recriada possibilita adquirir um pouco mais de terra. Esse método de cálculo foi registrado por diversos autores que analisaram a formação de patrimônio de agricultores (Heredia, 1979; Garcia Jr., 1989; Woortmann \& Woortmann, 1997; Schröder, 2004). A seca, forçando o agricultor a se desfazer ou consumir patrimônio, provoca prejuízo sério quando não existem alternativas como regadio ou política pública. Mas, o que é prejuízo para o lavrador pode se converter em ganhos para outros grupos sociais, que se aproveitam de situações vantajosas criadas às vezes pela política pública - créditos, contratos, obras públicas -, outras vezes pela própria estrutura desigual da distribuição de renda.
Secas, assim, acentuam desigualdades sociais, conforme resumiu magistralmente Patativa do Assaré $(1978$, p. 89) no poema "Triste partida". Na estiagem forte, quando o lavrador se vê obrigado a se desfazer do patrimônio amealhado ao longo da vida, "logo aparece / feliz fazendeiro / e por pouco dinheiro / the compra o que tem". O efeito social da seca é profundamente diferente para quem tem ou não tem renda, acentua desigualdades, provoca consequências danosas, mobiliza recursos públicos que beneficiam interesses privados. As estiagens, quando vêm com força, atingem com mais brutalidade aos lavradores e aos pobres.

No caso do vale do rio Jequitinhonha, essas constatações têm grande importância. Por ser situado em grande parte no domínio do Semiárido, num encontro dos biomas Cerrado, Caatinga e Mata Atlântica, secas atingem esta região de formas muito diferentes, como observaram Pereira (1969) e Andrade (1986). Mas, constantemente, vão encontrar uma população expressiva de agricultores familiares que compõe o grosso dessa sociedade rural e contava, na década de 2010 , média de $40 \%$ da população dos municípios, contrastando com médias muito inferiores em Minas Gerais e no Brasil (FJP, 2018).

Desde os anos 1960, um conjunto de programas públicos orientados para o mundo rural tem prejudicado muito esses agricultores. São programas focados na privatização de recursos naturais, como barragens, mineração e implantação de monoculturas - na região foi implantada a maior área contínua de eucaliptais do planeta. Como o valor à produção é agregado em outras regiões que beneficiam a matéria-prima, esses programas trouxeram poucos efeitos positivos para a renda rural no vale do Jequitinhonha (Calixto et al., 2009; Ribeiro, 2013). No entanto, os maciços de eucaliptos privatizaram 
milhares de hectares de áreas de terras comunais, destruíram, monopolizaram ou comprometeram centenas de nascentes e corpos d'água (Lima, 2013; FJP, 2018). Com escassez de fontes, o acesso à água passou a ser restrito e nas ocasiões de seca a população rural passou a depender, muitas vezes, de relações pessoais e da interveniência de agentes públicos. Em algumas situações, o poder público transformou a cessão da água em poder pessoal, operando a denominada "indústria da seca" (Silva, 2007; Silva et al., 2020).

\section{Pesquisa}

A seca prolongada desencadeia ações, salienta perspectivas e fundamenta narrativas que entram em conflito na lida pelo acesso às fontes e ao abastecimento de água. Lidar com a seca significa, necessariamente, se acercar de conflitos (Silva, 2007), definir prioridades e práticas (Polleto, 2001), optar entre técnicas de diferentes custos (Silva et al., 2020).

Agricultores geralmente falam e refletem muito sobre água, e mais ainda sobre as secas (Ribeiro \& Galizoni, 2003). Com isso, influenciam mediadores: sindicalistas, lideranças de associações e comunidades, que também refletem sobre a seca, comparam suas intensidades, consequências e conhecem em detalhe as situações vivenciadas nos municípios em que atuam (Silva et al., 2020). As agências públicas acompanham as secas, reagem às demandas de agricultores e mediadores, criam programas e atuam seguindo as possibilidades de combinar recursos e necessidades (Araújo et al., 2010; Assis, 2012).

Portanto, para compreender essas diferentes vozes foi preciso analisar falas e atitudes desses dois segmentos que se manifestam sobre secas. De um lado, técnicos e gestores públicos de órgãos e governos municipais com ações sobre recursos hídricos. De outro, famílias rurais das bacias hidrográficas do Jequitinhonha e seus principais mediadores, como dirigentes dos sindicatos de trabalhadores rurais e de associações comunitárias. Aqui, a atitude de pesquisa foi inspirada nas perspectivas de Bartlett \& Vavrus (2017), que enfatizaram a necessidade de articular dimensões da cultura, contexto, espaço e lugar em estudo de casos.

No Médio Jequitinhonha, as comunidades rurais são unidades de demarcação territorial e de relações sociais, conduzidas pelos próprios lavradores. São pautadas por relações de parentesco, compadrio e vizinhança, organizadas e participativas, que procuram criar soluções próprias para seus problemas. Parte da solidez dos laços dessas comunidades de agricultores se deve aos vínculos religiosos que têm por origem as CEBs (Comunidades Eclesiais de Base); outras comunidades foram animadas pelos sindicatos de trabalhadores rurais (Ribeiro, 2010).

Sindicatos de Trabalhadores Rurais (STRs) são os principais interlocutores dos lavradores dos municípios. Frutos de organização e luta de comunidades, têm base social participativa, trajetórias e caminhadas próprias. São compostos por agricultores familiares, posseiros, agregados e assentados e atuam em diversas áreas temáticas: jovens, crianças, mulheres, luta pela terra, educação e desenvolvimento. Geralmente se organizam em grupos de trabalho, segmentados em comissões que desenvolvem as atividades com as comunidades rurais. Organizam o trabalho no espaço por meio de setores, comunidades que atuam juntas numa mesma grande região; também se organizam por meio de delegados de base, lavradores que têm inter- 
locução com o STR nas comunidades e vice-versa. Os STRs, pela capilaridade e representatividade nas comunidades rurais, são organizações constantemente acionadas pelas famílias na busca de acesso à água (Galizoni, 2013).

Em situações críticas de secas, nos pequenos municípios do Jequitinhonha, as prefeituras são os locais acionados para atender as famílias rurais em situação de falta de água. Prefeituras se mobilizam nas ações de emergência, seja escavando poços, construindo barramentos ou, mais frequentemente, abastecendo a população por meio de caminhões-pipas. Nas prefeituras, essas ações geralmente são lideradas por secretários municipais de Agricultura, os departamentos procurados pelas comunidades e famílias de agricultores quando há falta de água (Silva et al., 2020).

Para analisar as informações vivas - como definiu Queiroz (1991) - que conformam as narrativas e atitudes dos informantes da pesquisa, foram combinadas técnicas distribuídas no tempo e espaço.

Primeiro, era preciso compreender percepções e atitudes em situações críticas de escassez de água. Mas era necessário também entender como atitudes orientadas por demandas individuais se transformavam em ações coletivas e comunitárias: afinal, como a comunidade metamorfoseava suas demandas? Haveria articulação ou atritos destas com as políticas públicas? Essas questões foram expostas e debatidas com agricultores(as) em sete comunidades rurais, distribuídas por cinco municí- pios do Médio Jequitinhonha: Aguada Boa (município de Araçuaí), Córrego do Rocha (município de Chapada do Norte), Tamanduá e Almas (município de Virgem da Lapa), Aredó e Gameleira (município de Medina) e Córrego do Ouro (município de Cachoeira de Pajeú). Entre todas, somente nesta última comunidade agricultores não enfrentavam forte restrição de acesso à água.

Em todas as localidades foram usadas as técnicas qualitativas de grupo focal (Poupart et al., 2008), com entrevistas coletivas feitas em profundidade, buscando sempre compreender a perspectiva da família nuclear e a gênese da atuação coletiva (Ostrom, 1990) ${ }^{1}$. A equipe de pesquisadores promovia na localidade uma reunião previamente agendada com representantes da associação comunitária, mas aberta a toda comunidade. Na reunião prévia, os pesquisadores se apresentavam, explicavam os objetivos da pesquisa e solicitavam o consentimento da comunidade para fazer o estudo. Nesse momento, os membros da associação conheciam os objetivos da pesquisa, tiravam dúvidas, faziam comentários e deliberavam sobre a conveniência da pesquisa.

Dado o consentimento, na reunião os pesquisadores faziam um levantamento, por meio do mapeamento, das famílias e da situação da água na localidade. A seguir apresentavam critérios de seleção para compor o grupo focal, contemplando diversidade de sexo, grupos etários, composição das famílias, volume de produção e acesso à água; era pedido aos presentes que indicassem membros de

\footnotetext{
${ }^{1}$ Partiu-se das premissas de Elinor Ostrom (1990) para compreender princípios comunitários que regem o conjunto de recursos comuns (CPR) de longa duração, conforme conceituação da própria autora. Ostrom definiu oito princípios que ajudam a explicar a robustez de CPRs: fronteiras claramente definidas, congruência entre regras de apropriação e provisão e as condições locais, mecanismos de escolhas coletivas, monitoramento, sanções graduadas, mecanismos de resolução de conflitos, reconhecimento mínimo do direito a se organizar, e para CPRs que são partes de sistemas mais amplos: apropriação, provisão, monitoramento, aplicação, mecanismos de resolução de conflitos e atividades de governança são organizados em múltiplas camadas de empreendimentos aninhados.
} 
famílias com essas características para compor os grupos focais. Selecionadas entre oito e dez pessoas por comunidade para participar do grupo focal, era marcada a data, pois a entrevista e o debate coletivo ocorriam em data pré-agendada. Na condução dos grupos focais, os pesquisadores usavam roteiros, pré-testados, com perguntas provocadoras sobre fontes de água, situações de escassez de água, estratégias familiares e comunitárias, avaliação de projetos e programas de abastecimento, visando investigar o alcance dos programas, os seus resultados e os impactos no local. Os grupos focais duraram de duas a três horas, eram gravados e a equipe de pesquisadores se dividia entre mediadores dos debates e observadores que anotavam falas e comportamentos corporais, conforme é praxe em pesquisas que usam a técnica (Bauer \& Gaskell, 2002).

Para pesquisar as narrativas de lideranças sindicais, foram realizadas entrevistas individuais em profundidade (Queiroz, 1991). Nessas entrevistas, nos municípios de Chapada do Norte, Virgem da Lapa, Araçuaí, Medina e Cachoeira do Pajeú, foi realizado levantamento dos programas relacionados à água executados ou reivindicados pela sociedade civil, investigando as parcerias construídas e buscando avaliar os programas executados. Os dirigentes de sindicatos, por seu turno, todos também lavradores, eram ao mesmo tempo representados, representantes e mediadores, além de participar dos Conselhos Municipais de Desenvolvimento Rural Sustentável, órgãos que influenciam ativamente as administrações municipais sobre água (Silva et al., 2020). Dessa forma, tinham perspectivas privilegiadas, para dentro das comunidades e para ações públicas, mas que poderiam se traduzir em reflexões maduras sobre a seca. Utilizou-se roteiro de temas articulando técnicas de histórias de vida e testemunhos (Bosi, 1983; Queiroz, 1991; Hobsbawm \& Ranger, 2015). As entrevistas foram feitas na sede dos sindicatos ou nas residências das lideranças, duraram em média duas horas e ocorreram mais de uma vez. Foram entrevistados(as) um(a) representante em cada localidade, indicados(as) pelas diretorias dos sindicatos.

Por fim, foram entrevistados, nos cinco municípios, gestores públicos responsáveis por ações com recursos hídricos: secretários de agricultura, principalmente, mas também técnicos da Copanor (Copasa Serviços de Saneamento Integrado do Norte e Nordeste de Minas Gerais S/A). Foi usado o mesmo instrumento de pesquisa em profundidade descrito acima. As entrevistas buscaram analisar as narrativas e mapear os diversos programas públicos de conservação, abastecimento e distribuição de água, investigando processos decisórios, parcerias, alcances e resultados para a população local (Maingueneau, 2006). As entrevistas foram previamente agendadas e ocorreram nas sedes das secretarias, durante o expediente, o que se mostrou muito oportuno, porque tornou possível observar a dinâmica de trabalho desses gestores do abastecimento, pois nas salas de espera, quase sempre lotadas, estavam lavradores aguardando decisões sobre consertos de bombas d'água comunitárias, rotas de caminhão-pipa e outras demandas por água. E como frequentemente essas demandas adentravam a sala do secretário, as interrupções se tornaram tão ricas para conhecer o tema quanto a própria entrevista.

A pesquisa ocorreu sempre na estação seca, coordenando o período de investigação num mesmo município, entrevistando sequencialmente comunidades, sindicatos e gestores públicos. Para tratamento e análise dos dados foram consultados como apoio outros estudos e pesquisas sobre a região. 


\section{Resultados}

\subsection{Lavradores e águas}

Grosso modo, a extensa área do vale do rio Jequitinhonha pode ser dividida em três Territórios: Alto, Médio e Baixo (Brasil, 2005). Essa territorialização é usada com muita frequência por agricultores, mediadores e associações de prefeituras; por isso também é adotada neste artigo.

O Território do Médio Jequitinhonha fica todo situado na demarcação do Semiárido feita pelo Governo Federal: a média histórica de precipitação fica abaixo de 1.000 milímetros por ano, o período anual de seca é bem marcado, as chuvas são escassas e concentradas em poucos meses (MIN, 2006). É marcado pela fertilidade natural dos terrenos e por vegetação de transição entre Cerrado, Mata Attântica e Caatinga. No Território há concentração da terra em fazendas de gado, que usam a terra como fonte do mando e prestígio usado na política. Mas isso não significou que na região as pequenas explorações familiares estivessem ausentes. Ao contrário, as famílias de lavradores constituíram comunidades rurais que se consolidaram e construíram seus próprios destinos com base em relações de parentesco, compadrio e vizinhança (Ribeiro, 2010).

No Médio Jequitinhonha existem diferentes formas de acesso à terra - o que é uma especificidade regional - e estas criaram sujeitos e categorias de lavradores que conformam a base dos sindicatos de trabalhadores rurais e estão ocultas sob o conceito de agricultores familiares. São principalmente herdeiros: lavradores com pedaço de terra próprio recebido por herança; posseiros: lavradores que por meio de seu trabalho possearam glebas de terra e criaram direitos reconhecidos pela sociedade abrangente, mas frágeis no aspecto formal; ou agregados: lavradores que têm produção autônoma, mas acesso frágil à terra.

Os agregados, inseridos nas fazendas, não estabeleciam relação trabalhista com os fazendeiros e sim relações de reciprocidade - troca quase sempre desigual, mas troca - que têm sua origem nos dons naturais da terra. A agregação, antes de ser relação de trabalho, era uma combinação entre dois indivíduos ou duas famílias que, por força de acordos, se transformava em direitos. De acordo com Ribeiro (2013, p. 15): "O agregado é um sujeito social contraditório, pois é definido por duas referências que a história tornou opostas: não tem terra e tem produção autônoma". Este é o caso de um agregado da comunidade de Rochedo que, em situação de conflito, alegava que seu direito à terra era fundamentado na combinação que fizera com o fazendeiro e que os filhos deste não tinham o direito de rompê-la, o que os filhos do fazendeiro, apesar de contrafeitos, reconheciam. O temor desse agregado era a dúvida: se seus próprios filhos, após sua morte, teriam acesso àquele direito. Uma parcela razoável dos lavradores do Médio Jequitinhonha é, assim, composta por agregados, com acesso precário à terra, que passa pela mediação dos fazendeiros. Em boa parte das vezes, a desagregação significou a perda do acesso aos terrenos e a migração definitiva, mas em alguns municípios os agregados construíram uma trajetória de organização política baseada na luta pela terra.

A categoria posseiro, para as famílias de agricultores, é um conceito que vem relacionado, quase sempre, ao conflito pela terra e à desagregação. Para os lavradores, quem detém a posse é dono da terra porque construiu um direito por meio 
de seu trabalho, mas tem uma formalização frágil desse direito; o termo posseiro tem a marca jurídica contraposta à formalização da terra em propriedade (Ribeiro, 2010).

Outra grande parte das famílias de agricultores do Médio Jequitinhonha é formada por moradores de herança. Ilustra esta categoria o caso de um lavrador da comunidade de Aredó, que usa um terreno em conjunto com seu pai e mais quatro irmãos. De acordo com ele, a família não quis partilhar a terra porque, desse modo, todos têm liberdade de plantar, de escolher a área que vai usar, pois de dois em dois anos é importante fazer rotação de terreno para plantio, e assim é melhor o terreno da família não estar fragmentado.

A terra, de acordo com lavradores do Médio Jequitinhonha, tem vários veios: para feijão é uma terra, para mandioca é outra e para abacaxi é outra ainda. Algumas glebas apresentam elevada fertilidade natural para lavoura, que é identificada por meio dos arvoredos como a jurema, jurema branca, canela, aroeira, ingá, juazeiro, marinheiro, moreira, timbó, pau-de-colher, angico, carne de vaca, quitoco, assa-peixe, malva, cai-cai e neve. Tendo essa vegetação, a pessoa pode plantar sem receio. Já os terrenos em que nascem andrequicé e quina de vara são ruins para lavoura. A variação da vegetação indica as diferenças de fertilidade e qualidade das terras.

A localização no relevo também é importante para classificação das terras: há os terrenos de bai$x a d a$, úmidos, férteis e próximos aos rios; existem também os terrenos altos, nos topes e declives dos morros, apresentando muitas vezes uma terra que não segura a água, passa a chuva e lava a terra. Não sendo terrenos bons para plantio, só é possível plantar abacaxi, que não é uma planta exigente. A textura - que se percebe ao pegar na mão - também é importante para identificar a terra: aquelas que apresentam composição de barro são mais conservadeiras de umidade, seguram o molhado, a vegetação é mais desenvolvida, produzem melhor se chover pouco; em algumas comunidades a melhor terra tem tonalidade preta e é mais propícia para laranja, feijão, milho, cana, bananeira e outras lavouras de consumo. Já a terra arenosa, "gera" mais rápido a lavoura, mas também as plantas morrem mais rápido, porque segura menos água; essa é própria para plantio da mandioca, andu e feijão catador. Conhecendo os tipos de terra, os lavradores determinam os usos.

Nas baixadas as famílias plantam milho e feijão, plantas de ciclos rápidos. Plantam primeiro milho e depois vários tipos de feijão: de corda, catador e carioquinha. Fazem pelo menos dois plantios de feijão em diferentes estações do ano: no tempo das águas, plantando no tempo das chuvas (outubro/novembro), e nas neblinas, plantando nos brejos no mês de março. Plantam, junto com a roça de milho, feijão, abóbora, abacaxi, laranja, fava e cana. Cultivam em consórcio, misturado. Em algumas comunidades as lavouras são feitas na beira dos córregos porque lá estão as melhores manchas de terra.

A lavoura de mandioca é a mais importante para o sustento das famílias do Médio Jequitinhonha, porque tem diversidade de uso muito grande. Alimenta galinha, gado, porco, serve para fazer farinha, polvilho ou goma, comer cozida, frita ou assada. A farinha de mandioca é também importante como moeda de troca entre famílias de lavradores, na feira livre semanal ou entre vizinhos.

Quase todas as famílias possuem um quintal em volta da casa com diversidade de plantas, frutas e remédios, muita fartura. Nos quintais, as famílias 
organizam os reservatórios de água para abastecimento. Neles, a reutilização é também forma corrente de economizar e fazer o recurso "render": a água usada para lavar louças ou no banho é reaproveitada para molhar as plantas e canteiros.

As águas do Médio Jequitinhonha mineiro apresentam uma particularidade com relação ao Semiárido brasileiro: a presença de nascentes ${ }^{2}$.

Nascentes e minas são categorias diferentes no sistema de classificação das fontes de água usado por lavradores do Médio Jequitinhonha. Apesar de serem tipos de nascentes, são conhecidas como nascentes aquelas águas que brotam da terra com volume forte e correm formando pequenos córregos. As águas de nascentes geralmente são captadas por sistemas de mangueiras. Muitas vezes, logo abaixo da nascente é construído pequeno barramento que não interrompe o fluxo da água, mas permite juntar volume para alimentar as mangueiras que abastecem as casas. Já as minas são áreas úmidas, onde a água fica "marejando", molhando o terreno, mas não escorre formando córregos. As minas são indicadas por vegetação, como os capins cebolinha e cabelo de sapo e também pelo arbusto chamado orelha de cachorro. Em algumas comunidades as minas têm também o nome de minério ou mineração. As famílias afirmam que nem todas águas de nascentes ou minas são boas para beber; algumas são salobras.

As águas das minas são captadas por meio de técnica denominada como cacimba: a cava rasa feita pelas famílias onde a água brota. Às vezes são feitos sistemas integrados de cacimbas, com três cavas em sequência, muitas vezes interligadas, sendo que a água da primeira cava é usada exclusivamente para beber, já a água retirada da segunda e terceira cavas é utilizada para lavar roupas, vasilhas e banhos. É importante ressaltar que a água é retirada das cavas para uso, ou seja: não se banha ou lava roupa e vasilha dentro das cacimbas; este cuidado auxilia na conservação da qualidade das águas. Há também cacimbas feitas em leitos de córregos secos ou intermitentes. Lavradores estudam a vegetação, observam onde é mais verde e fazem a cava. As cacimbas sempre são muito asseadas, zeladas, cobertas com tábuas ou tela para proteger as águas. Às vezes os lavradores descobrem o lugar propício para cacimba por meio do lacrimal, local onde a água mareja sobre a terra. Outras vezes precisam quebrar pedras para fazer cacimbas, porque a água pode estar entre duas camadas de rocha.

Lavradores ensinam que as técnicas de cacimba e cisterna têm pequena diferença. A cacimba é rasa e a cisterna é profunda, mas às vezes a diferença não é só de profundidade, e sim que para a cacimba basta uma cava simples no solo e a cisterna exige encamisamento, revestimento da cava com cimento que eleva um pouco o nível da água. A utilização da cacimba ou da cisterna tem a ver com a forma como a água brota: a cacimba é usada quando a água está mais superficial; já para a cisterna é preciso aprofundar para descobrir a água, para a água subir ao nível do chão.

\footnotetext{
2 A maior parte do solo do Semiárido brasileiro é formado por rochas cristalinas que apresentam dificuldades para aprovisionamento e aproveitamento de água subterrânea, seja por sua impermeabilidade seja pela presença de sais, que tornam a água salobra e com baixa potabilidade (Schistek, 2001). Poletto (2001, p. 12) esclarece essa diferenciação interna do Semiárido: "Parte dele já é árida, desertificada. Algumas outras áreas estão em processo intenso de degradação, constituindo o polígono da seca em que a população sofre muito mais quando as chuvas se tornam mais raras". Ver também Andrade (1986).
} 
As comunidades rurais construíram sistema elaborado de conhecimento das fontes naturais de água associado à forma como a água surge no ambiente, ao seu aspecto, paladar e, consequentemente, aos possíveis usos (Tabela 1). Esse sistema cultural é base de gestão comunitária e embasa manejo, acesso e partilha das fontes naturais entre as famílias. As melhores fontes de água, as que apresentam as características mais puras, são destinadas também para os usos humanos mais nobres: beber e cozinhar; as águas menos apreciadas também têm seu valor para usos específicos, como lavar roupa e dessedentar animais. Cada fonte se relaciona a um conjunto de técnicas para o acesso familiar e comunitário. Assim, uma refinada classificação das fontes fundamenta formas de gerir a água que buscam zelar pelo manancial, disciplinar o uso e nortear o consumo.
Mas monoculturas de eucalipto nas áreas de recargas, exploração das rochas de granito e técnicas de agricultura intensiva têm generalizado processos drásticos de secamento de mananciais. A expropriação de terras para a monocultura do eucalipto trouxe, além disso, duas consequências: a intensificação do uso da terra nas grotas e boqueirões onde vivem agricultores familiares, e o desmatamento da vegetação nativa nas cabeceiras e nas áreas de recarga dos mananciais.

Comunidades rurais do Médio Jequitinhonha e sindicatos de trabalhadores rurais mudaram a percepção sobre as grandes secas. Muito antigamente, explicavam, havia abundância de água natural nas nascentes correntes, córregos e rios vivos. Grandes secas eram, principalmente, sinônimo de falta de chuva para fazer produzir a lavoura de sequeiro, plantada em outubro ou novembro. Então, seca

TABELA 1 - Classificação elaborada pelas famílias rurais pesquisadas das águas de fontes naturais.

\begin{tabular}{|c|c|c|c|c|}
\hline Cristalina & $\begin{array}{l}\text { fina e leve no sabor, } \\
\text { alva, sadia e asseada }\end{array}$ & beber e cozinhar & $\begin{array}{l}\text { nascentes, brotos d'água e } \\
\text { minas }\end{array}$ & $\begin{array}{l}\text { sistemas de mangueira e caixa, } \\
\text { cacimbas, cisternas e poços }\end{array}$ \\
\hline Azul & $\begin{array}{c}\text { menos fina que a } \\
\text { cristalina e mais fina } \\
\text { que a grossa }\end{array}$ & $\begin{array}{l}\text { beber, cozinhar e demais } \\
\text { usos domésticos }\end{array}$ & $\begin{array}{l}\text { nascentes, brotos d'água e } \\
\text { minas }\end{array}$ & $\begin{array}{l}\text { sistemas de mangueira e caixa, } \\
\text { cacimbas, cisternas }\end{array}$ \\
\hline Grossa & $\begin{array}{l}\text { pesada no gosto, } \\
\text { amarelada, mexida }\end{array}$ & $\begin{array}{l}\text { lavar louças, roupas, banhar, } \\
\text { dar para os animais }\end{array}$ & córregos, ribeirões e rios & $\begin{array}{c}\text { caixa e sistemas de mangueira, } \\
\text { latas e baldes }\end{array}$ \\
\hline Nova & $\begin{array}{l}\text { água de enchente, } \\
\text { impura }\end{array}$ & $\begin{array}{c}\text { não tem uso, causa gripes e } \\
\text { doenças }\end{array}$ & córregos, rios e ribeirões & não é coletada \\
\hline
\end{tabular}

FONTE: Pesquisa de Campo, 2013/2019. 
era associada à escassez de alimentos, à morte das lavouras plantadas, mas nunca à falta de água, porque as fontes minguavam, mas não secavam, e água não faltava. Foi a partir dos anos 1970 que a seca "mudou de feição" e as grandes secas foram se associando cada vez mais à falta de água, em consequência da morte de nascentes.

A mudança, esclareciam agricultores e mediadores, estava ligada à modernização da agricultura e pecuária, às tomadas de terras, às monoculturas de eucalipto. A extração abusiva de recursos e a privatização da natureza se refletiram no secamento de mananciais. Às comunidades rurais e aos sindicatos restou lidar com a diminuição das fontes e a escassez.

Lavradores e seus sindicatos precisaram se organizar para lidar com a restrição de oferta de água e "capturar" programas de abastecimento. Assim, comunidades rurais, que em tempos passados geriram costumeiramente as fontes naturais de água, passaram a lidar com fontes social e politicamente construídas para se abastecer.

Para os lavradores, a época mais crítica da seca no ano é entre os meses de agosto e setembro. Entretanto, para algumas localidades essa temporalidade foi alterada, pois a seca prolongada e os secamentos de nascentes ampliaram os efeitos da escassez de água para além dos períodos naturais de estiagem. A comunidade de Tamanduá, município de Virgem da Lapa, por exemplo, era abastecida por caminhão-pipa durante todo o ano: as parcas chuvas eram insuficientes para regularizar suas fontes e a escassez de água já não era relacionada somente com a estiagem anual.

Quando a água escasseava, a rotina diária tendia a ficar mais difícil para as mulheres. Eram elas que decidiam sobre as prioridades do uso do- méstico da água. De acordo com uma agricultora da comunidade de Tamanduá, a prioridade era ter água para beber, mas era preciso sempre ter controle, sempre "regular":

Aqui nós temos uma reserva de três caixas d'água de 1.000 litros. Na realidade gastamos menos água pra beber, o gasto é mais pra lidar em casa: roupa para lavar, cozinhar, para essas coisas. Pra lavar vasilha tenho dois tachos, ponho 8 litros em um e 8 no outro: lavo em um e enxáguo no outro, a água rende mais. Fica como se fosse uma torneira: saindo assim economiza mais. Para limpar a casa uso dois baldinhos de água e compro um detergente pra dar um cheirinho. Faço um milagre! Tem que ser com pouca água. A gente banha com um balde de 12 litros. Meu marido estranha! Ele morava na beira do rio Jequitinhonha e tinha água à vontade, e ai ele veio pra cá. Às vezes ele não consegue banhar com um balde de 12 litros, tem que ser dois baldes. Eu fico brigando com ele: "-Você tem que aprender banhar com um balde só!" Nós temos que conseguir levar esses 3 mil litros até a próxima vez que chegar um pipa aqui na comunidade.

Além da escassez para consumo doméstico, a estiagem prolongada rebatia na produção. De acordo com um lavrador da comunidade de Almas:

Já tem dois anos que nós não fazemos o feijoal. Ai, vem só comprando... Passou muito o tempo da chuva e as nascentes encurtaram. Acontece é o seguinte: os pais da gente falavam que tinha a época do feijão das águas, mas não plantava, plantava era o feijão de feijoal [plantado no início da seca, em áreas úmidas], roçava a terra e ai trabalhava aquela terra lambuzada de lama, pra plantar ali, mas porque chovia. Já chegou chover 40 dias e 40 noites sem parar. (...) Eu tenho 67 anos, e minha família nunca deixou de plantar feijão de feijoal, e agora já tem dois anos que nós não plantamos. 
As famílias buscavam fazer rearranjos produtivos para lidar com a estiagem: reduziam o tamanho da roça de mantimento, cultivavam plantas mais resistentes à falta de água, como os feijões de corda, catador e andu em lugar de feijão-de-arranca, o feijão comercial mais vulgar, diminuíam ou deixavam de fazer horta, reduziam ou deixavam de criar gado bovino e ampliavam, quando possível, a criação de galinhas.

Nos períodos de auge da escassez de chuvas, a compra de água pelas famílias se tornou frequente. Adquiriam água de "pipeiros" (donos de caminhão-pipa), transformando a escassez da água em situações de muita precisão de dinheiro. A aquisição de água tinha um crivo muito forte nas áreas rurais: eram principalmente famílias que tinham renda monetária regular, com aposentados ou migrantes sazonais, que compravam. As demais famílias pressionavam as prefeituras por abastecimento pelo caminhão-pipa. O preço de água de um caminhão-pipa variava entre os municípios: em Araçuaí cerca de 10.000 litros custavam R\$ 160,00 e o "pipeiro" pagava R\$ 63,62 para a Copasa, companhia estatal de saneamento, para encher o caminhão; em Chapada do Norte o preço da água de um caminhão-pipa era $\mathrm{R} \$ 200,00$ pelos mesmos 10.000 litros; em Virgem da Lapa as famílias que compravam esse mesmo volume de água pagavam $\mathrm{R} \$ 150,00$ se fosse água tratada pela Copasa ou $\mathrm{R} \$$ 100,00 se fosse água coletada diretamente no rio Jequitinhonha, sem tratamento.

Apesar de ser aparentemente a prática de abastecimento mais fácil - um caminhão que leva água para as famílias necessitadas -, é a técnica que mais recebia críticas da população e dos sindicatos de trabalhadores rurais. Eram criticadas a insuficiência de quantidade, de qualidade, a irregularidade na distribuição, o estímulo às disputas entre famílias para abastecimento e, principalmente, as relações clientelistas com as prefeituras.

A opção por perfurar poços artesianos para abastecimento de água nas comunidades rurais também enfrentava resistência dos sindicatos de trabalhadores rurais e das comunidades rurais. Muitos poços tinham vazão baixa e não asseguravam água definitiva, não atendiam a todas as famílias ou jorravam água salobra. Parte dos poços tubulares era perfurada na beira dos rios, longe das moradas. Mas a opção de agências públicas por poços artesianos também implicou alterações nas formas de gestão comunitária da água. Representou horizonte novo de regulação da água, que, com algumas exceções, tendia a se resolver por meio de uma distribuição concentrada.

A água extraída do poço artesiano era considerada mais "fácil" pelos lavradores, chegava à casa de quase todas as famílias, reduzindo a penosidade do trabalho, mas não chegava em quantidade suficiente para todos e, por ser uma água mediada pela prefeitura, não tinha - pelo menos no período pesquisado - o consumo disciplinado pelas normas comunitárias, criando sempre muito conflito. As normas comunitárias de regulação das águas não foram transferidas automaticamente das nascentes, cacimbas e cisternas para os poços. Ao contrário, a gestão dos poços artesianos inaugurou um diferencial em relação à gestão: a necessidade de mediação política externa. A administração do poço artesiano exigia formalização, que quase sempre se concretizava numa associação. A regulação comunitária tradicional se assentava em relações de parentesco, os sujeitos eram coletivos: famílias, que estabeleciam relações de trocas recíprocas. $\mathrm{Na}$ associação, parte das vezes havia inversão desses 
pactos costumeiros, as decisões se personalizavam no presidente e as mediações do poder político local eram constantes na manutenção do sistema.

Na seca prolongada, o acesso ao abastecimento foi sempre muito incerto. As famílias rurais não tinham garantias de que iriam conseguir a quantidade e a qualidade de água que necessitavam. É por isso que comunidades e famílias rurais buscavam sempre pelo que denominavam como água definitiva, aquela que daria segurança ao abastecimento. No dizer do senhor Antônio Figueiredo Murta, lavrador da comunidade de Almas: "Água é um terror aqui na comunidade”. Mas, enquanto as comunidades não conseguiam acessar a água definitiva, desenvolveram estratégias para lidar com a mobilidade das fontes, isto é, articulavam estratégias de abastecimento no correr do ano e das estações.

Na comunidade de Aguada Boa as famílias se abasteciam combinando: (i) a água de uma pequena mina que abastecia cinco famílias; (ii) um poço artesiano que abastecia dois terços das famílias da comunidade, mas como a vazão era baixa havia rodízio de abastecimento a cada três dias; (iii) cisterna de placa de 16.000 litros, coletora de água de chuva, do Programa Um Milhão de Cisternas, presente em quase todos os domicílios; e (iv) a tentativa de se inserir no programa de construção de barraginhas para ampliar seus reservatórios, fortalecer mananciais e alcançar regularidade mínima de acesso à água ${ }^{3}$.

Assim, para construir sistemas de abastecimento que suprissem as necessidades domésticas e produtivas, as comunidades precisavam articular fontes naturais - nascentes/minas, cacimbas, cisternas/poços cavados manualmente, córregos e rios -, que estavam secando, com fontes socialmente construídas por meio de programas e projetos públicos de acesso à água: poços tubulares ou artesianos, barragens, barraginhas, cisterna da placa para coletar água da chuva (ou "caixa de goteira") e caminhão-pipa. Combinavam formas coletivas, como reservatórios, poços tubulares ou artesianos, e formas privativas das famílias, como a cisterna de placa da coleta de água de chuva, barraginhas e tanques ou poços-baianos (ver Quadro 1).

\section{2. Água e poder público}

Na situação crítica da grande seca nos pequenos municípios do Médio Jequitinhonha, prefeituras são desaguadouros das demandas das famílias rurais em situação de vulnerabilidade hídrica.

Para as secretarias municipais de Agricultura, o sentimento frente à situação da estiagem severa era de impotência de decisão e falta de recursos frente ao grande afluxo de famílias requerendo cotidianamente abastecimento de água para consumo doméstico. A agenda de distribuição de água no período da estiagem era extensa e dispersa pelo território: havia demandas diversificadas e cotidianas, que implicavam também logísticas complexas.

Em Virgem da Lapa, o secretário de Agricultura relatava que:

Você vê o povo pedindo água e não tem por onde correr... O caminhão-pipa da prefeitura está quebrado, aí o pessoal fica assim: "-Moço, manda uma água para nós porque lá em casa não tem água nem pra

\footnotetext{
3 Barraginha é uma técnica de pequenas escavações em áreas altas com o propósito de reter água para alimentar o lençol freático e proteger nascentes de assoreamentos (Silva et al., 2020).
} 
QUADRO 1 - Principais fontes construídas por políticas ou programas públicos.

\begin{tabular}{|c|}
\hline $\begin{array}{l}\text { P1MC*: Programa Um Milhão de Cisternas (Programa de Formação e Mobilização Social para a Convivência com o Semiárido), iniciativ } \\
\text { da Articulação do Semiárido Brasileiro (ASA), busca universalizar o acesso à água potável para famílias do Semiárido brasileiro; constroer } \\
\text { de forma participativa cisternas de placas de cimento de } 16 \text { mil litros, acopladas aos telhados das casas, recebendo de uma bica móvel a águ } \\
\text { que cai no telhado. Programa público cogerido pela sociedade civil e governo federal. }\end{array}$ \\
\hline $\begin{array}{l}1+2^{*} \text { : Programa Uma Terra e Duas Águas, coordenado pela ASA, apoia a construção, para as famílias que têm a cisterna de } 16 \text { mil litros, de } \\
\text { utras cisternas de } 52 \text { mil litros com objetivos de fornecer água para produzir alimentos e dessedentar animais. }\end{array}$ \\
\hline $\begin{array}{l}\text { Água Para Todos*: Programa do Governo Federal do Brasil (Decreto n }{ }^{\circ} 7535 \text {, de } 26 \text { de julho de 2011), que reunia medidas preventivas e } \\
\text { corretivas para o convívio com a seca onde a precipitação pluviométrica é baixa. Consistiu na distribuição de caixas de polietileno de } 16 \text { mil } \\
\text { litros para armazenar água de chuva. }\end{array}$ \\
\hline $\begin{array}{l}\text { Caminhão-pipa**: Caminhão-pipa tem capacidade para transportar de } 8 \text { a } 10 \text { mil litros de água e é uma das principais ações municipais para } \\
\text { enfrentar a escassez de água. }\end{array}$ \\
\hline $\begin{array}{l}\text { Poços artesianos**: Poços tubulares para acessar água do lençol freático ou subterrâneo, perfurados pelas prefeituras, COPANOR (COPASA } \\
\text { Serviços de Saneamento Integrado do Norte e Nordeste de Minas Gerais) ou particulares. }\end{array}$ \\
\hline
\end{tabular}

FONTE: * Silva et al. (2020); ${ }^{* *}$ Informações coletadas por meio de pesquisa de campo, 2018/2019.

fazer um café!” Outro me fala: “-Oh! meus porcos, minhas galinhas! Estão todos morrendo de sede, manda um caminhão pipa com água". E a gente sem o caminhão-pipa, fica complicado.

Em Araçuaí, como nos outros municípios, as ações municipais de abastecimento que predominavam na seca para as comunidades rurais eram os caminhões-pipa. Das 67 comunidades rurais do município, 37 recebiam regularmente caminhão-pipa a partir de junho e agosto. Eram cerca de 10.000 litros - volume médio transportado por um caminhão - a cada dois meses por família; o volume independia do tamanho e da composição da família. Aágua era depositada na cisterna de placas de recolher água de chuva do telhado. Do ponto de vista de gestão e logística, para esta administração era preferível depositar uma quantidade maior de água e, assim, estabelecer um tempo mais longo de retorno a cada localidade. Eram usados seis caminhões-pipa: um era da Prefeitura Municipal, outro foi cedido pelo Departamento Estadual de Estradas e Rodagem, dois eram contratados pela Defesa Civil e dois eram alugados pela Prefeitura. Cada caminhão alugado representava despesa média de $\mathrm{R} \$ 13.000,00$ por mês para a Prefeitura. As rotas dos caminhões-pipa eram coordenadas pela Secretaria de Agricultura, tendo como base as famílias a serem atendidas, que seguiam demandas das associações comunitárias. É importante ressaltar que a associação fazia o levantamento, mas o pedido por água era individual de cada família. Um dos caminhões era usado quase que somente para atender demandas de escolas rurais.

Na longa estiagem depois de 2013, tanto a cidade de Chapada do Norte quanto as comunidades das áreas rurais precisavam ser atendidas com caminhões-pipa. A Secretaria de Agricultura do município fez um levantamento e mapeou rios e córregos do município; dos 74 corpos d'água iden- 
tificados, apenas três rios maiores vertiam: Setúbal, Fanado e Araçuaí, mas todos com vazão diminuída (Lima, 2013). O rio Capivari, que passa ao lado da cidade e a abastecia, tinha seu curso interrompido na estação da seca. O secretário de Agricultura e o STR do município associavam o secamento deste rio a práticas agrícolas de uma empresa nas cabeceiras do rio, que drenavam as nascentes para fazer um viveiro de eucaliptos. A Secretaria Municipal de Agricultura fotografou, registrou e denunciou para o órgão ambiental de Minas Gerais. Depois de oito dias, em ofício, a Secretaria foi notificada que a empresa estava em posição legal, tinha outorga para retirada da água; aí, afirmou o Secretário, a Prefeitura não teve mais o que fazer.

A população de Chapada do Norte contava em 2010 com 3.000 habitantes na cidade e 10.400 habitantes na área rural (IBGE, 2010). O abastecimento da cidade era feito pela COPANOR (COPASA Serviços de Saneamento Integrado do Norte e Nordeste de Minas Gerais S/A.) por meio de quatro caminhões-pipa; a Prefeitura desconhecia o planejamento e as rotas urbanas desses caminhões e contava com apenas um caminhão-pipa para atender toda a população rural, distribuída por 82 comunidades. Como o município tinha situação de emergência reconhecida pelo Ministério da Integração Nacional, o Exército Brasileiro coordenava a distribuição de água para a população rural, estimando 20 litros de água tratada por pessoa/dia. Como o atendimento do Exército era intermitente, parte da demanda era atendida pela Prefeitura e por caminhões-pipa particulares, que vendiam água para famílias rurais ou urbanas.

Mas, essa forma de abastecimento por meio de caminhão-pipa recebia críticas também do poder público, pois era um serviço de custo elevado e logística sempre complexa - muitas vezes, um caminhão-pipa fazia várias viagens para abastecer precariamente poucas famílias numa comunidade.

Boa parte dos municípios afetados pela estiagem prolongada no Médio Jequitinhonha decretou situação de emergência. Esse processo levava ao reconhecimento da situação de estiagem pelo Ministério da Integração Nacional, que, mediante levantamento de dados ambientais, sociais e econômicos relacionados à seca, baixava portaria reconhecendo a emergência. A partir daí, os municípios podiam ser atendidos pelo Exército ou pela Defesa Civil, podiam acessar programas e ações emergenciais cujos recursos são coordenados pelo governo estadual. Assim, o governo federal reconhece e o governo do estado atende à emergência, o que às vezes também gerava dissonâncias.

A capacidade de armazenamento da cisterna de placas do P1MC foi de grande utilidade durante a seca. O reservatório familiar de 16.000 litros que coletava água da chuva era importante pela abrangência, capilaridade e, principalmente, pela gestão compartilhada das prioridades entre organizações da sociedade civil e governos. Mas, a água captada no período da chuva pela cisterna de placa não era suficiente para passar período prolongado da seca. Antônio das Graças, presidente do STR de Araçuaí, explicou que, como as demais fontes secaram ou não deram conta de atender ao consumo familiar, o uso da água da chuva foi ampliado para além do consumo doméstico - serviu para molhar canteiros ou dessedentar criações de terreiro - e por isso se esgotava antes de iniciado novo período chuvoso.

As cisternas de placa, simultaneamente, aumentaram a solicitação nas prefeituras, pois as famílias passaram a estocar mais água. Apesar do Programa definir explicitamente que as cisternas 
de placas somente deveriam ser abastecidas com água da chuva, não foi o que aconteceu no período de escassez prolongada. Como eram os principais recipientes disponíveis para as famílias rurais, assim que as cisternas de placas iam se esvaziando, estas buscavam completá-las com outra água, principalmente águas de caminhão-pipa. A possibilidade de estocar água, aliada à insegurança do atendimento (as famílias não tinham nenhuma certeza que iriam ser atendidas!), fazia com que a demanda chegasse constantemente aos poderes públicos, cobrando o abastecimento dos reservatórios com águas fluviais. Assim, na emergência, a restrição do $\mathrm{P} 1 \mathrm{MC}$ acabava por ser ignorada pelo município e o uso dado no local divergia das diretrizes estabelecidas. Entretanto, a avaliação que os secretários de Agricultura faziam deste programa era extremamente positiva: as famílias enchiam o reservatório com a água da chuva e, com os reservatórios cheios, detinham pelo menos as reservas iniciais de água para o período de seca. Avaliavam que, se não fosse pelas cisternas de coleta de água da chuva, que na seca se transformaram em reservatório precioso, a situação das famílias rurais seria pior e, consequentemente, maior a pressão sobre as prefeituras. A cobertura espacial do P1MC nas localidades e no período estudados atingia $90 \%$ das famílias.

Durante a grande seca de 2013/2019, havia mais dois programas de abastecimento de água. $\mathrm{O}$ "Programa Uma Terra e Duas Águas" (P1+2), na sequência do P1MC, usando a cisterna calçadão, que captava 52.000 litros de água, estava em período experimental de implantação. E o "Programa Água para Todos", vinculado ao governo estadual, tinha por base o abastecimento humano por meio da perfuração de poços tubulares e ou artesianos.
Avaliando suas atividades ligadas à água, secretários municipais de Agricultura consideravam que tinham equipes pequenas de funcionários $(3,5$ pessoas em média) para lidar com temas da agricultura, agricultura familiar, ambiente e abastecimento de água no rural. As secretarias municipais de Agricultura não tinham orçamentos próprios, precisavam disputar anualmente no orçamento global da prefeitura recursos para suas atividades, mas estes eram sempre incertos. E as secretarias de Agricultura trabalhavam isoladas: não se comunicavam com as outras secretarias, havia poucas ações conjuntas. Apesar das parcerias com os Conselhos Municipais de Desenvolvimento Rural Sustentável, com Escolas Famílias Agrícolas, Universidades, Embrapa e IDENE, eram as secretarias que se acionava em situações de emergência. Também eram grandes as dificuldades quando ocorria troca da gestão municipal: equipamentos eram sucateados, equipes, mudadas e ações, interrompidas.

Mesmo no auge da grande seca, as prefeituras não dispunham de orçamentos próprios para secretarias de agricultura e água, mesmo considerando que, nesses municípios, parte muito relevante da população vivia no meio rural. E a gestão do abastecimento era sempre baseada em arranjos improvisados, precários e frágeis. Embora existissem programas federais, estaduais e ações da sociedade civil para promover o acesso das comunidades rurais à água, eles poucos se comunicavam entre si, não criavam soluções estruturantes e desperdiçavam recursos. As prefeituras não tinham planos municipais de convivência com o Semiárido nem havia orçamento específico para lidar com o acesso à água para a população rural. As secretarias gerenciavam emergência sem planejamento ou recursos. 
Nesse caos que se tornava o abastecimento, agricultores evitavam depender de uma única fonte de água: buscavam água onde podiam, de todas as fontes, porque essa foi a marca dessa quadra difícil que durou tanto tempo.

\section{Considerações finais}

Nos períodos de estiagem do Jequitinhonha, longos ou aqueles corriqueiros de todo ano, é precária a gestão pública das águas. Apesar das secas recorrentes, para as famílias rurais dessa porção do Semiárido mineiro o acesso à água sempre é negociado com muita dificuldade.

Nesse cenário, o município é certamente a melhor escala para pensar o abastecimento. É para esta unidade da Federação que convergem e são executados os principais programas de acesso à água, e mesmo que não tenham sido criados naquela instância, é no âmbito do local, da gestão pública municipal, que se revelam os aspectos mais dramáticos da escassez da água e da gestão da privação.

Aágua - por ser essencial para a vida humana - deveria ser obrigatoriamente transversal a toda gestão pública. No entanto, não há esse entendimento em nenhuma esfera do poder público, que, ao contrário, é segmentado: a água urbana é de obrigação da companhia estadual e nessa esfera a prefeitura pouco ou quase nada pode opinar. $\mathrm{O}$ abastecimento da população rural, de acordo com os sindicatos de trabalhadores rurais, é uma terra sem lei, no limbo da divisão entre poderes municipais, estadual e federal. Os programas e os gastos, na maioria, são criados nas esferas federal e estadual, mas nas situações de emergência a descoordenação na gestão pública se manifesta, com resultados danosos para a população rural.
A gestão estatal, quase sempre, separava o abastecimento de água das ações e programas de conservação das fontes. Nas ações dos órgãos públicos e prefeituras não havia contrapartidas ambientais para os programas de abastecimento e tampouco prioridade na conservação de mananciais - que ainda podiam ser considerados vantagens relativas do Médio Jequitinhonha no cenário do Semiárido. Prefeituras lidavam com o abastecimento de água para comunidades rurais administrando demandas emergenciais.

A gestão da água passava a ser individualizada, conduzida por normas pouco claras em cada localidade. Água era ao mesmo tempo assunto premente e periférico, e a resposta do setor público ficava aquém da importância dada pelas famílias rurais. Sindicalistas percebiam que o abastecimento de água para o rural no Médio Jequitinhonha não era gerido pelas instâncias governamentais como um problema público. Ao contrário, era percebido como um problema a ser resolvido, em última instância, pelas próprias famílias e comunidades, ou seja: as famílias deveriam buscar a sua água definitiva.

Ações desencontradas de governo, clientelismo na distribuição da água, famílias rurais buscando água do modo que fosse possível. Este era o cenário da emergência, que produziu muitas narrativas, vozes dissonantes que raramente convergiam ao tratar das consequências da seca. Comunidades, apoiadas pelos sindicatos de trabalhadores rurais, perseguiam a intricada articulação de iniciativas públicas para garantir seu acesso à água, estabeleciam normas de partilha comunitárias para gestão da água e buscavam assegurar o acesso mínimo, uma margem mesmo que ínfima de segurança de abastecimento para as famílias, inventando soluções coletivas que combinavam tecnologias sociais, programas 
clientelistas, políticas de combate à seca e técnicas produtivas adaptadas. Mobilizavam todas as táticas possíveis para compor a estratégia de travessia da seca que custava a acabar.

\section{Referências}

Andrade, M. C de. Terra e homem no Nordeste. São Paulo, Brasiliense, 1986.

Araújo, V. M.; Ribeiro E. M.; Reis, R. P. Águas no rural do semiárido mineiro: uma análise das iniciativas de regularização do abastecimento em Januária. Organizações Rurais e Agroindustriais, 12, 23-38, 2010. Disponível em: http:// repositorio.ufla.br/jspui/handle/1/176

Assis, T. R. P. Sociedade civil e a construção de políticas públicas na região semiárida brasileira: o caso do Programa Um Milhão de Cisternas rurais (P1MC). Revista de Politicas Publicas (UFMA), 16, 179-189, 2012. Disponível em: http://www.periodicoseletronicos.ufma.br/index.php/ rppublica

Bartlett, L.; Vavrus, F. Estudos de Caso Comparado. Educação \& Realidade, Porto Alegre, 42(3), 899-920, jul/set. 2017. doi: 10.1590/2175-623668636

Bauer, M. W.; Gaskell, G. Pesquisa qualitativa com texto, imagem e som. Petrópolis: Vozes, 2002.

Bosi, E. Memória e sociedade: lembrança de velhos. São Paulo: T. A. Queiroz Editor, 1983.

Brasil. MDA/SDT. Marco referencial para apoio ao desenvolvimento de territórios rurais. Série Documentos Institucionais 02-2005. Brasília: SDT, 2005.

Calixto, J. S.; Ribeiro, E. M.; Galizoni, F. M.; Macedo, R. L. G. Trabalho, terra e geração de renda em três décadas de reflorestamentos no alto Jequitinhonha. Rev. Econ. Sociol. Rural, Brasília, 47(2), 519-538, jun. 2009. doi: 10.1590/ S0103-20032009000200009

Costa, K. V. Permanência e transformação na Agricultura Familiar: um estudo de caso sobre a resistência dos agricul-

\section{Agradecimentos}

A pesquisa que originou este artigo foi financiada pelo CNPq e Fapemig. tores familiares no Submédio São Francisco. Recife, Tese (Doutorado em Sociologia) - UFPE, 2014.

Cunha, E. Os sertões. Rio de Janeiro: Livraria Francisco Alves, 1967.

Dayrell, C. A. Os geraizeiros descem as serras. In: Luz, C.; Dayrell, C. A. Cerrado e desenvolvimento, tradição e atualidade. Montes Claros: CAA/NM, 2000.

Freyre, G. Nordeste. Rio de Janeiro, José Olympio, 1968.

FJP - Fundação João Pinheiro. Plano de Desenvolvimento para o Vale do Jequitinhonha. Belo Horizonte: FJP, 2018.

Galizoni, F. M. Lavradores, água e lavouras: estudos sobre a gestão camponesa da água no Alto Jequitinhonha. Belo Horizonte: Editora UFMG, 2013.

Galizoni, F. M.; Ribeiro, E. M. Bem comum e normas costumeiras: a ética das águas em comunidades rurais de Minas Gerais. Ambiente \& Sociedade, 14, 77-94, 2011. doi: 1015901414-753X2011000100005

Garcia Júnior, A. R. Sul caminho do roçado: estratégia camponesa e transformação social. São Paulo: Marco Zero; Brasília: Editora UnB, 1989.

Gomes, G. M. Novas secas em velhos sertões. Brasília: IPEA, 2001.

Guimarães Duque, J. O Nordeste e as lavouras xerófilas. 4. ed. Fortaleza: Banco do Nordeste do Brasil, 2004.

Heredia, B. M. A morada da vida: trabalho familiar de pequenos produtores no Nordeste do Brasil. Rio de Janeiro: Paz e Terra, 1979.

Hobsbawm, E.; Ranger, T. (Orgs.) A invenção das tradições. São Paulo: Paz e Terra, 2015. 
IBGE - Instituto Brasileiro de Geografia e Estatística. Censo Demográfico 2010. Brasília, 2010.

INMET - Instituto Nacional de Meteorologia. Disponível em: <https://portal.inmet.gov.br>. Acesso em: 14 ago. 2020. Leal. V. N. Coronelismo, enxada e voto. São Paulo: Alfa Ômega, 1975.

Lima, V. M. P. Secas e águas - alterações na dinâmica da água no Alto Jequitinhonha. In: Galizoni, F. M. Lavradores, água e lavouras: estudos sobre a gestão camponesa da água no Alto Jequitinhonha. Belo Horizonte: Editora UFMG, 2013.

Maingueneau, D. Termos-chave da análise do discurso. Belo Horizonte: Editora UFMG, 2006.

Malvezzi, R. Semiárido: uma visão holística. Brasília: Confea, 2007.

Medeiros, C. A andança no vasto, o fogo no vazio: paisagem sociais e ambientais da perspectiva de realocação do Parque Nacional Grande Sertão Veredas, no norte mineiro. In: Comerford, J.; Carneiro, A.; Dainese, G. et al. (Org.). Giros etnográficos em Minas Gerais: casa, comida, prosa, festa, política, briga e o diabo. Rio de Janeiro: 7 Letras; Faperj, 2015.

MIN - Ministério da Integração Nacional. Nova delimitação do Semiárido brasileiro, 2006. Disponível em: $<\mathrm{http}$ ://www. mi.gov.br/c/document_library/get_file?uuid $=0 \mathrm{aa} 2 \mathrm{~b} 9 \mathrm{~b} 5$-aa4d-4b55-a6e1-82faf0762763\&groupId=24915>. Acesso em: 23 jun. 2016.

Ostrom, E. Governing the commons. New York: Cambridge University Press, 1990.

Patativa do Assaré. Cante lá que eu canto cá: filosofia de um cantador nordestino. Petrópolis: Editora Vozes, 1978.

Paula, H. Montes Claros: sua história, sua gente e seus costumes. Rio de Janeiro: IBGE, 1957.

Pereira, L. O município de Araçuai. Belo Horizonte: Impressa Oficial, 1969.

Polleto, I. Da indústria da seca para a convivência com o semiárido brasileiro. In: Cáritas Brasileira, Comissão Pastoral da Terra, FIAN. Água de chuva: o segredo de convivência com o semiárido. São: Paulo, Paulinas, 2001.
Poupart, J.; Deslauriers, J-P.; Groulx, L-H.; Laperrière, A.; Mayer, R.; Pires, Á. P. (Orgs.). A pesquisa qualitativa: enfoques epistemológicos e metodológicos. Petrópolis: Vozes, 2008.

Queiroz, M. I. P. de. Variação sobre a técnica de gravador no registro da informação viva. São Paulo: T. A. Queiroz Editor, 1991.

Ribeiro, E. M. Agregados e fazendas no nordeste de Minas Gerais. Estudos Sociedade e Agricultura, 18(2), 393-433, 2010. Disponível em https://revistaesa.com/ojs/index.php/ esa/article/view/330

Ribeiro, E. M. Sete estudos sobre a agricultura familiar do Vale do Jequitinhonha. Porto Alegre: Editora UFRGS, 2013.

Ribeiro, E. M.; Galizoni, F. M. Água, população rural e políticas de gestão: o caso do vale do Jequitinhonha, Minas Gerais. Ambiente \& Sociedade, V-VI(1-2), 129-146, jan./ jul. 2003. Disponível em: https://www.scielo.br/scielo. php?script=sci_serial\&pid=1414-753X\&lng=pt\&nrm=iso

Ribeiro, E. M.; Galizoni, F. M. A arte da catira - negócios e reprodução familiar de sitiantes mineiros. Revista Brasileira de Ciências Sociais, 22(64), 65-74, jun. 2007. Disponível em: https://www.scielo.br/pdf/rbcsoc/v22n64/a05v2264.pdf

Schistek, H. Como conviver com o semiárido. In: Cáritas Brasileira, Comissão Pastoral da Terra, FIAN. Água de chuva: o segredo de convivência com o semiárido. São Paulo: Paulinas, 2001.

Schröder, M. A demanda financeira dos agricultores do sertão do Pajeú. In: Abramovay, R. (Org.) Laços financeiros na luta pela pobreza. São Paulo: Annablume; Fapesp, 2004.

Silva, R. M. A. Entre o combate à seca e a convivência com o semiárido. Revista Econômica do Nordeste, 38, 2007. Disponível em: https://ren.emnuvens.com.br

Silva, J. L.; Ribeiro, A. E. M.; Lima, V. M. P.; Heller, L. As secas no Jequitinhonha: demandas, técnicas e custos do abastecimento no semiárido de Minas Gerais. Revista Brasileira de Estudos Urbanos e Regionais, 22, E202013, 2020. doi: 10.22296/2317-1529.rbeur.202013

Woortmann, E. F.; Woortmann, K. O trabalho da terra: a lógica e a simbólica da lavoura camponesa. Brasília: Editora UnB, 1997. 